\title{
8q12 microduplication syndrome
}

INSERM

\section{Source}

INSERM. (1999). Orphanet: an online rare disease and orphan drug data base. 8912 microduplication syndrome. ORPHA:228399

The newly described 8q12 microduplication syndrome is associated with unusual and characteristic multi-organ clinical features, which include hearing loss, congenital heart defects, intellectual disability, hypotonia in infancy, and Duane anomaly (see this term). 